\title{
TURISMO SEXUAL DE CRIANÇAS E ADOLESCENTES: FUNCIONAMENTO E FORMAS DE ENFRENTAMENTO
}

Vanessa Hanayo Sakotani ${ }^{1}$, Renata Maria Coimbra Libório ${ }^{2}$

${ }^{1}$ Pedagogia, Departamento de Educação da Universidade Estadual Paulista - UNESP - Presidente Prudente. Departamento de Educação da Universidade Estadual Paulista - UNESP - Presidente Prudente. E-mail: Financiamento: FAPESP. hanayo sakotani@hotmail.com

\section{RESUMO}

O presente trabalho é um recorte de uma pesquisa de iniciação cientifica que caracterizou a exploração sexual de crianças e adolescentes. O recorte apresentado neste trabalho refere-se ao turismo sexual com o objetivo de descrever o funcionamento da rede e as formas de enfrentamento propostos pelos pesquisadores da área. Para a pesquisa dos artigos científicos de língua portuguesa e inglesa publicado entre 2000 a 2011 relacionados ao tema, foram utilizados os unitermos turismo sexual e sexual tourism na base de periódicos da CAPES. A metodologia utilizada foi a pesquisa bibliográfica, a revisão sistemática de leitura e para a análise foi utilizada a análise de conteúdo temática.

Palavras-chave: Turismo sexual, crianças e adolescentes, revisão bibliográfica, funcionamento

\section{INTRODUÇÃO E OBJETIVOS}

O presente trabalho é uma parte de pesquisa de iniciação científica realizada com financiamento da FAPESP. O objetivo central da pesquisa foi elaborar uma caracterização atual da exploração sexual de crianças e adolescentes, através de pesquisa bibliográfica de artigos publicados em inglês e português, disponíveis no Portal da CAPES (Coordenação de

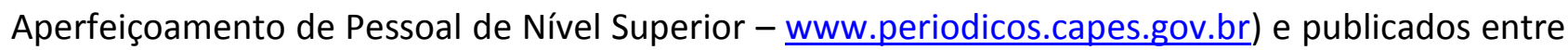
os anos de 2000 a 2011 .

Optamos por apresentar a parte referente à caracterização do turismo sexual visando a descrição e análise das formas de funcionamento das redes de exploração sexual e abordagens de enfrentamento propostos por estudiosos da área. Os unitermos utilizados para a busca dos artigos foram: turismo sexual e sexual tourism.

A violência sexual contra crianças e adolescentes representa uma violação aos seus direitos e é composta por duas categorias, o abuso e a exploração sexual. A exploração sexual diferencia-se do abuso sexual principalmente por àquela envolve comercialização e remuneração de diferentes naturezas, enquanto este não há trocas comerciais. Esta distinção entre exploração 
e abuso sexual é frequentemente confundida e muitas vezes tratada como se fossem o mesmo fenômeno.

A exploração sexual de crianças e adolescentes é dividida em quatro modalidades, sendo o turismo sexual compreendido como o uso de crianças e adolescentes para satisfação sexual, sendo que geralmente aquele que compra sexo sai de seu país de origem (na maioria das vezes, países desenvolvidos) para ter atos sexuais em outro país (na maioria das vezes, países subdesenvolvidos ou em desenvolvimento) com crianças e adolescentes. O turismo sexual pode também ocorrer dentro de um único país, com exploradores e explorados da mesma nacionalidade, envolvendo deslocamento para outras regiões turísticas, onde ocorre a exploração sexual.

\section{METODOLOGIA}

Este trabalho é uma pesquisa bibliográfica de artigos científicos de língua inglesa e portuguesa, publicados entre os anos de 2000 a 2011, disponíveis nos periódicos do Portal da CAPES, sendo a busca dos artigos feita pelos unitermos turismo sexual e sexual tourism.

Após a coleta dos artigos, estes passaram por uma revisão sistemática de leitura que de acordo com Sampaio e Mancini (2007) consiste em

[...] uma forma de pesquisa que utiliza como fonte de dados a literatura sobre determinado tema. Esse tipo de investigação disponibiliza um resumo das evidências relacionadas a uma estratégia de intervenção específica, mediante a aplicação de métodos explícitos e sistematizados de busca, apreciação crítica e síntese da informação selecionada. (SAMPAIO e MANCINI, 2007, p.84)

De acordo com Sampaio e Mancini (2007), a revisão sistemática passa pelas seguintes etapas: "definindo a pergunta", "buscando a evidência", "revisando e selecionando os estudos", "analisando as qualidades metodológicas dos estudos" e "apresentando os resultados".

Na primeira etapa, "definindo a pergunta", é necessário que haja uma pergunta clara e explicita que guiará esta revisão sistemática de acordo com o objetivo da pesquisa. Os autores destacam que esta pergunta deve ser clara e bem formulada. No presente trabalho, a pergunta é "Como funciona as redes de turismo sexual de crianças e adolescentes e quais as formas e meios de enfrentar e combater esta problemática?".

Em "buscando evidências", é necessário que sejam selecionadas as palavras chaves para a busca do material, as estratégias que serão utilizadas e a fonte em que será feita as buscas. Neste 
caso, as palavras chaves usadas foram "turismo sexual" e "sexual tourism" e a fonte foi a base de periódicos da CAPES.

$\mathrm{Na}$ terceira etapa (revisando e selecionando estudos), foram selecionados os artigos através da leitura de resumos e abstracts com base na pergunta norteadora, ou seja, foram selecionados artigos científicos, de língua inglesa e portuguesa, publicadas entre 2000 a 2011, e que abordavam assuntos de funcionamento e formas de enfrentamento ao turismo sexual de crianças e adolescentes.

Em "analisando as qualidades metodológicas dos estudos", para assegurar a qualidade da pesquisa, foram selecionados artigos científicos de Qualis alto (A e B).

E por fim, na última etapa, são apresentados os resultados da pesquisa.

Após a revisão sistemática de leitura, os dados foram organizados de acordo com a análise de conteúdo temática, em que os dados são organizados através de categorias expressivas e significativas. Neste caso, as categorias que foram recortadas da pesquisa foram o funcionamento do turismo sexual de crianças e adolescentes e as formas de enfrentamento.

\section{RESULTADOS}

Os resultados obtidos na presente pesquisa em relação ao funcionamento e formas de enfrentamento do turismo sexual estão apresentados abaixo.

Tabela 1. Funcionamento das redes de turismo sexual

Categorias encontradas

Número e frequência de artigos encontrados que abordam essas

Serviços sexuais são oferecidos em hotéis, praias (a noite), salas ou quartos em que as crianças moram, alojamentos/pousadas, esquinas, canteiros de obras desertos;

Pessoas saem de países desenvolvidos para ter relações sexuais com crianças em países subdesenvolvidos ou em desenvolvimento. categorias

\begin{tabular}{l|c|c} 
& & \\
\hline$\quad$ Estados Unidos: maiores clientes & 1 & $25 \%$ \\
\hline$>\quad$ Prevalência do turismo sexual: Brasil, índia, Sri Lanka, & 3 & $75 \%$ \\
\hline Tailândia, Filipinas, Ilha do Caribe;
\end{tabular}

Fonte : Pesquisa de Campo, 2011-2012 
Tabela 2. Propostas de Enfrentamento do Turismo sexual

\begin{tabular}{l}
\hline \begin{tabular}{l} 
Categorias encontradas \\
\hline$>\quad$ Criação de banco de dados de criminosos sexuais;
\end{tabular} \\
\hline$>\quad$ Aplicação de multas pesadas e prisão para donos de \\
agências de turismo que promovem o turismo sexual; \\
\hline$>\quad$ Intensificar a punição dos criminosos \\
\hline$>\quad$ Importante reconhecer a dificuldade no combate ao \\
turismo sexual devido às legislações diferentes em cada país \\
\hline Campo, 2011-2012
\end{tabular}

Fonte : Pesquisa de Campo, 2011-2012

\section{DISCUSSÃO}

No que concerne ao funcionamento do turismo sexual de crianças e adolescentes, Desai (2008) que pesquisou o fenômeno em destaque na India, revela que houve um aumento do turismo sexual no país e diminuição em outros países conhecidos por oferecer este tipo de serviço, tal como a Tailândia.

Desai (2008) e Miller (2011), ao pesquisarem a India e o Sri Lanka respectivamente, destacam que os serviços sexuais são oferecidos normalmente em hotéis, praias (a noite), salas ou quartos em que as crianças moram, alojamentos/pousadas, esquinas, canteiros de obras desertos.

Segundo Desai (2008), os clientes estrangeiros preferem os hotéis para terem relações sexuais, enquanto clientes locais preferem pousadas/alojamentos ou salas de bares para estes fins. Os turistas conseguem informações sobre o turismo sexual do local através de fornecedores de crianças e massagistas.

Newman et al. (2011), que pesquisaram o fenômeno em diversos países, revelam que as crianças eram traficadas para locais em que havia grande demanda por corpos infantis, entretanto atualmente, os criminosos e clientes tem fácil acesso a países em que as crianças estão mais vulneráveis à exploração sexual. Logo, o tráfico é descartado em razão desta facilidade associada ao turismo.

Os autores destacam que os clientes geralmente saem de países desenvolvidos para ter relações sexuais com crianças de países subdesenvolvidos ou em desenvolvimento. Esta informação corresponde ao conceito de turismo sexual apresentado neste trabalho.

Em relação as formas de enfrentamento, Newman et al. (2011) apresentam formas de enfrentamento do turismo sexual de alguns países. A Costa Rica socializa com outras nações uma lista de criminosos sexuais; no Reino Unido, o criminoso é obrigado a notificar as autoridades ao 
sair do país; na Colômbia, as agências de turismo são obrigadas a cumprir um Código de Conduta que proíbe este tipo de atividade; nos Estados Unidos e na Itália são previstas multas pesadas e prisão para os responsáveis de agências de turismo que beneficiam a exploração sexual; e na China, utilizam-se da lei de obscenidades para punir criminosos sexuais.

Os autores sugerem que a criação de um banco de dados dos criminosos sexuais seria de extrema utilidade. Os mesmos revelam a dificuldade de punir os criminosos através de leis quando o crime aconteceu no exterior, ou seja, em outro país com legislações diferentes.

Newman et al. (2011) além de citarem formas de enfrentamento, destacam os desafios em relação a punição dos criminosos, pois muitas vezes perde-se contato com a vítima; a vítima pode ser subornada ou ameaçada pelo criminoso para ficar em silêncio; barreiras culturais e linguísticas, desestruturação das autoridades locais; dificuldade em determinar a idade das vítimas já que estas não portam documento de identidade e não há mecanismos para estimar a idade destas. Em relação às vítimas, estas tem dificuldade de processar e apresentar queixas sobre o criminoso sexual.

Os autores destacam a dificuldade de estabelecer uma idade mínima para a relação sexual consensual, já que cada país tem sua legislação e diferentes ideias sobre maioridade e minoridade.

\section{CONCLUSÃO}

É possível concluir através dos dados apresentados nesta pesquisa que o turismo sexual é um fenômeno aparentemente invisível aos olhos da sociedade, pelo fato das atividades sexuais acontecerem em locais privados, tais como hotéis, pousadas, salas e quartos. Em locais públicos, as trocas sexuais acontecem no período da noite, geralmente em locais desertos nos quais não há circulação de muitas pessoas.

As pesquisas confirmam que os indivíduos que procuram por atividades sexuais são provenientes de países desenvolvidos, e cometem os atos sexuais em países subdesenvolvidos ou em desenvolvimento, tal como o próprio conceito é descrito. O destino dos clientes do comércio do sexo são estes países, pois as crianças são mais vulneráveis à exploração em razão de diversos fatores, mas principalmente pela privação econômica.

Quanto às formas de enfrentamento, o trabalho sugere algumas, entretanto, há desafios que são obstáculos para que as estratégias para o combate ao turismo sexual aconteçam de modo efetivo. Principalmente por envolver países diferentes (do cliente e do explorado) com legislações 
e processos legais divergentes que tem como principal consequência a impunidade dos criminosos.

\section{REFERÊNCIAS}

BANDYOPADHYAY, Ranfan and NASCIMENTO, Karina. "Where fantasy becomes reality": how tourism forces made Brazil a sexual playground. Journal of Sustainable Tourism, v. 18, n. 8, p. 933 - 949, nov. 2010. http://dx.doi.org/10.1080/09669582.2010.497220

DESAI, Murli. Challenges of Commercial Sexual Exploitation of Children in India Need for Legislative Reforms in Partnership with the Social-Work Profession. Asia Pacific Journal of Social Work and Development, v. 18, n. 1, p. 63 - 75, jun. 2008. http://dx.doi.org/10.1080/21650993.2008.9756033

MILLER, Jody. Beach boys or sexually exploited children? Competing narratives of sex tourism and their impact on young men in Sri Lanka's informal tourist economy. Crime, Law and Social Change, v. 56, n. 1, p. $485-508$, oct. 2011.

NEWMAN, William J.; HOLT, Ben W.; RABUN, John S.; PHILLIPS, Gary and SCOTT, Charles L. Child sex tourism: Extending the borders of sexual offender legislation. International Journal of Law and Psychiatry, v. 34, n. 2, p. 116 - 121, mar. 2011. http://dx.doi.org/10.1016/j.ijlp.2011.02.005

SAMPAIO, R. F.; MANCINI, M. C. Estudos de revisão sistemática: um guia para síntese criteriosa da evidência científica. Rev. bras. fisioter., São Carlos, v. 11, n. 1, p. 83-89, jan./fev. 2007. 